\title{
Development of ANN Model for Wind Speed Prediction as a Support for Early Warning System
}

\author{
Ivan Marović, ${ }^{1}$ Ivana Sušanj, ${ }^{2}$ and Nevenka Ožanić ${ }^{2}$ \\ ${ }^{1}$ Department of Construction Management and Technology, Faculty of Civil Engineering, University of Rijeka, \\ 51000 Rijeka, Croatia \\ ${ }^{2}$ Department of Hydraulic Engineering and Geotechnical Engineering, Faculty of Civil Engineering, University of Rijeka, \\ 51000 Rijeka, Croatia
}

Correspondence should be addressed to Ivana Sušanj; isusanj@uniri.hr

Received 28 September 2017; Accepted 28 November 2017; Published 20 December 2017

Academic Editor: Milos Knezevic

Copyright (C) 2017 Ivan Marović et al. This is an open access article distributed under the Creative Commons Attribution License, which permits unrestricted use, distribution, and reproduction in any medium, provided the original work is properly cited.

\begin{abstract}
The impact of natural disasters increases every year with more casualties and damage to property and the environment. Therefore, it is important to prevent consequences by implementation of the early warning system (EWS) in order to announce the possibility of the harmful phenomena occurrence. In this paper, focus is placed on the implementation of the EWS on the micro location in order to announce possible harmful phenomena occurrence caused by wind. In order to predict such phenomena (wind speed), an artificial neural network (ANN) prediction model is developed. The model is developed on the basis of the input data obtained by local meteorological station on the University of Rijeka campus area in the Republic of Croatia. The prediction model is validated and evaluated by visual and common calculation approaches, after which it was found that it is possible to perform very good wind speed prediction for time steps $\Delta t=1 \mathrm{~h}, \Delta t=3 \mathrm{~h}$, and $\Delta t=8 \mathrm{~h}$. The developed model is implemented in the EWS as a decision support for improvement of the existing "procedure plan in a case of the emergency caused by stormy wind or hurricane, snow and occurrence of the ice on the University of Rijeka campus."
\end{abstract}

\section{Introduction}

Today we are witnessing a high number of various natural harmful meteorological and hydrological phenomena, which increase every year with a greater number of casualties and damage to property and the environment. The impact of these disasters quickly propagates around the world irrespective of who or where we are [1]. To cope with such, a growing number of professionals and volunteers strive to help [2] by gaining knowledge and taking actions toward hazard, risk, vulnerability, resilience, and early warning systems, but such has not resulted in changing the practices of disaster management [3, 4]. Additionally, some natural hazards have continuous impact on a smaller scale, that is, location. Their rate of occurrence and the impact they make around bring importance of implementing the same disaster management principles as is on bigger scale.

In order to cope with such challenges, Quarantelli (1988) [5] argued that the preparation for and the response to disasters require well aligned communication and information flows, decision processes, and coordination structures. Such become basic elements of today's early warning systems (EWSs). According to the United Nations International Strategy for Disaster Reduction (UN/ISDR, 2006) [6], a complete and effective EWS includes four related elements: (i) risk knowledge, (ii) a monitoring and warning system service, (iii) dissemination and communication, and (iv) response capability.

Today, the implementation of artificial neural networks (ANN) in order to develop prediction models becomes very interesting research field. The usage of ANN in field of hydrology and meteorology is relatively new since the first application was noted in the early nineties. The first implementation of ANN in order to predict wind speed is noted by Lin et al. (1996) [7], Mohandes et al. (1998) [8], and Alexiadis et al. (1998) [9]. Also, in order to predict wind speed, recently numerous examples of ANN implementation are noted. Fonte et al. (2005) [10] in their paper introduced a prediction 


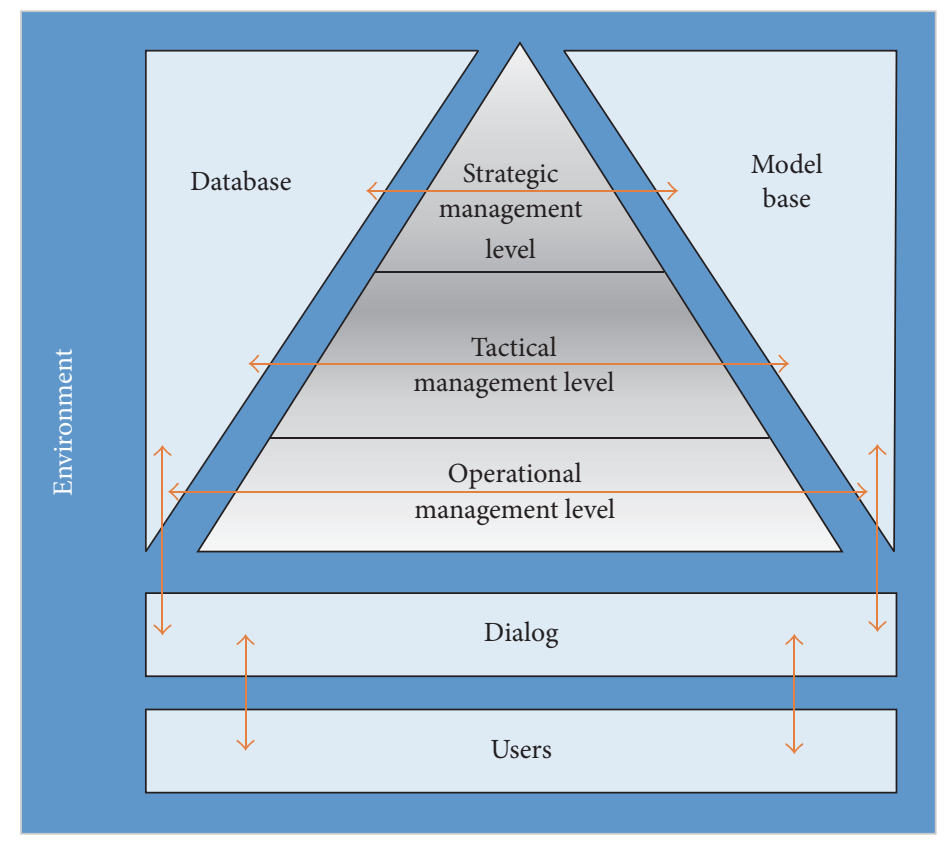

FIGURE 1: Structure of the decision support system for early warning management system.

of the average hourly wind speed, and Monfared et al. (2009) [11] in their paper introduced a new method based on ANN for better wind speed prediction performance presented. Pourmousavi Kani and Ardehali (2011) [12] introduced a very short-term wind speed prediction in their paper and Zhou et al. (2017) [13] presented a usage of ANN in order to establish the wind turbine fault early warning and diagnosis model. According to the aforementioned implementations of the ANN, development of such a prediction model in order to establish an EWS on the micro locations that are affected by the harmful effects of wind is not found and it needs to be better researched.

The goal of this research is to design and develop an ANN model in order to achieve a successful prediction of the wind speed on micro locations, based on data from local meteorological stations. The final aim and objective of the research is to implement a developed ANN wind speed prediction model in order to serve as decision support tool in an EWS.

This paper is organized as follows. Section 2 provides a research background of decision support as well as the methodology for development ANN prediction models as a tool for supporting decisions in EWS. In Section 3, the results of the proposed model are shown and discussed, with implementation in EWS on the micro location of University of Rijeka campus area. Finally, the conclusion and recommendations are presented in Section 4.

\section{Methodology}

Depending on the need of the business, different kinds of information systems are developed for different purposes. In general, different kinds of data and information are suitable for decision-making in different levels of organization hierarchy and require different information systems to be placed such as (i) Transaction Process Systems (TPS), (ii) Management Information Systems (MIS), (iii) Decision Support Systems (DSS), and (iv) Executive Support Systems (ESS) [16]. At the same time, each information system cannot fulfill complete information needs of each level. Therefore, overlapping of the systems is needed in order to preserve both information flows (from lower to upper level) and actions (from upper to lower level).

A structure of the proposed early warning management system (Figure 1) is based on Marović's previous research [17], where the "three decision levels" concept for urban infrastructure $[18,19]$ and spatial [17] management is proposed. The modular concept is based on DSS basic structure [20]: (i) database, (ii) model base, and (iii) dialog module. Interactions between modules are realized throughout the decision-making process at all management levels as they serve as meeting points of adequate models and data.

The first management level supports decision-makers at lowest operational management level. Beside its general function of supporting decision-making processes at operational level, it is a meeting point of data and information. Additionally, it provides information flows toward higher decision levels. It is a procedural level where problems are well defined and structured. The second management level deals with less defined and semistructured problems. On this level, tactical decisions are delivered, and it is a place where information basis and solutions are created. Based on applied models from model base (e.g., ANN), it gives alternatives and a basis for future decisions on strategic management level, which deals with even less defined and unstructured problems. At the third management level, based on the expert 
deliverables from the tactical level, a future development of the system is carried out. Strategies are formed, and they serve as frameworks for lower decision and management levels.

Outside factors from the environment greatly influence decision support system, as is shown in Figure 1, on both decision-making and whole management processes. Such structure is found to be adequate for various urban management systems, and its structure easily supports all phases of the decision-making in early warning systems.

In addition to the previously defined four elements, EWSs are specific to the context for which they are implemented. Glantz (2003) [21] described general principles that one should bear in mind: (i) continuity in operations, (ii) timely warnings, (iii) transparency, (iv) integration, (v) human capacity, (vi) flexibility, (vii) catalysts, and (viii) apolitical. It is important to take into account current and local information [22] as well as knowledge from past events (stored in a database) or grown structures [23]. In order to be efficient in emergencies, EWSs need to be relevant and user-oriented and allow interactions between all tools, decision-makers, experts, and stakeholders [24-26]. It can be seen as an information system which deals with various types of problems (from structured to unstructured). The harmful event prediction model based on ANN is in general developed under the monitoring and warning system service and becomes a valuable tool in the DSS's model base.

The development of ANN prediction model requires a number of technologies and areas of expertise. It is necessary to have an adequate set of data (from monitoring and/or collection of existing historical data) on the potential hazard area, real-time, and remote monitoring of trigger factors. On such a collection of data, the data analysis is made, which serves as a starting point on the prediction model development (testing, validation, and evaluation processes) [27]. Importing such a prediction model in an existing or the development of a new decision support system results in a supporting tool for public authorities and citizens in choosing the appropriate protection measures on time.

2.1. Development of Data-Driven ANN Prediction Models. As a continuation of previous authors' research $[14,15]$, a new prediction model based on ANN will be designed and developed for the wind speed prediction as a base for the EWS. Nowadays, the biggest problem in the development of the prediction models is their diversity of different approaches to the modeling process, their complexity, procedures for model validation and evaluation, and implementation of different and imprecise methodologies that can in the end lead to practical inapplicability. Therefore, the aforementioned methodology $[14,15]$ is developed on the basis of the general methodology guidelines suggested by Maier et al. (2010) [28] and consists of the precise procedural steps. These steps allow implementation of the model on the new case study with a defined approach to complete modeling process.

Within this paper, steps of the methodology for the development of the ANN model are going to be briefly described, while in the dissertation done by Sušanj (2017) [15] the detailed description of the methodology can be found. The developed methodology consists of the four main process groups: (i) monitoring, (ii) modeling, (iii) validation, and (iv) evaluation.

2.1.1. Monitoring. The first process group of the aforementioned methodology is the monitoring group, which refers to the procedures of collecting relevant data (both historical and data from monitoring) and how it should be conducted. It is very important that the specific amount of the relevant and accurate data is collected as well as the triggering factors for the purpose of the EWS development to be recognized.

2.1.2. Modeling. The second group refers to the modeling process comprising the implementation of the ANN. In this process, identification of the model input and output data has to be determined. Additionally, data preprocessing, elimination of data errors and division of data into training, validation, and evaluation sets have to be done. When data is prepared, the implementation of the ANN can be conducted.

In the proposed methodology [14, 15], the implementation of the Multiple Layer Perceptron (MLP) architecture with three layers (input, hidden, and output) is recommended. The input layer should be formed as a matrix of a meteorological time series data multiplied by weight coefficient $w_{k}$ that is obtained by learning algorithm in training process. The data should, in a hydrological and meteorological sense, have an influence on the output data. Therefore, it is very important that the input matrix is formed from at least ten previously measured data or one hour of measurements in each line of the matrix in order to allow the model insight into the meteorological condition in a given time period. The hidden layer of the model should consist of the ten neurons. The number of the neurons can be changed, but the previous research has shown that it will not necessary lead to model quality improvement. The output layer consists of the time series data that are supposed to be predicted. The model developer chooses the time prediction step, after which the process of the ANN training, validation, and evaluation can be conducted.

The quality and learning strength of the ANN model is based on the type of the activation functions and training algorithm that are used [29]. Activation functions are directing data between the layers and the training algorithm has the task of optimizing the weight coefficient $w_{k}$ in every iteration of the training process in order to provide a more accurate model response. It is recommended to choose nonlinear activation function and learning algorithm because of their adaptation ability on the nonlinear problems. Therefore, bipolar sigmoid activation functions and the LevenbergMarquardt learning algorithm are chosen. The schematic presentation for the ANN model development is shown in Figure 2.

After the architecture of the ANN model is defined and the training algorithm and prediction steps are chosen, the program packages in which the model will be programmed should be selected. There are a large number of the prepared program packages with prefabricated ANN models, but for this purpose completion of the whole programing process is advisable. Therefore, usage of the MATLAB (MathWorks, Natick, Massachusetts, USA) or any other programing software is recommended. After the model is programed, the 


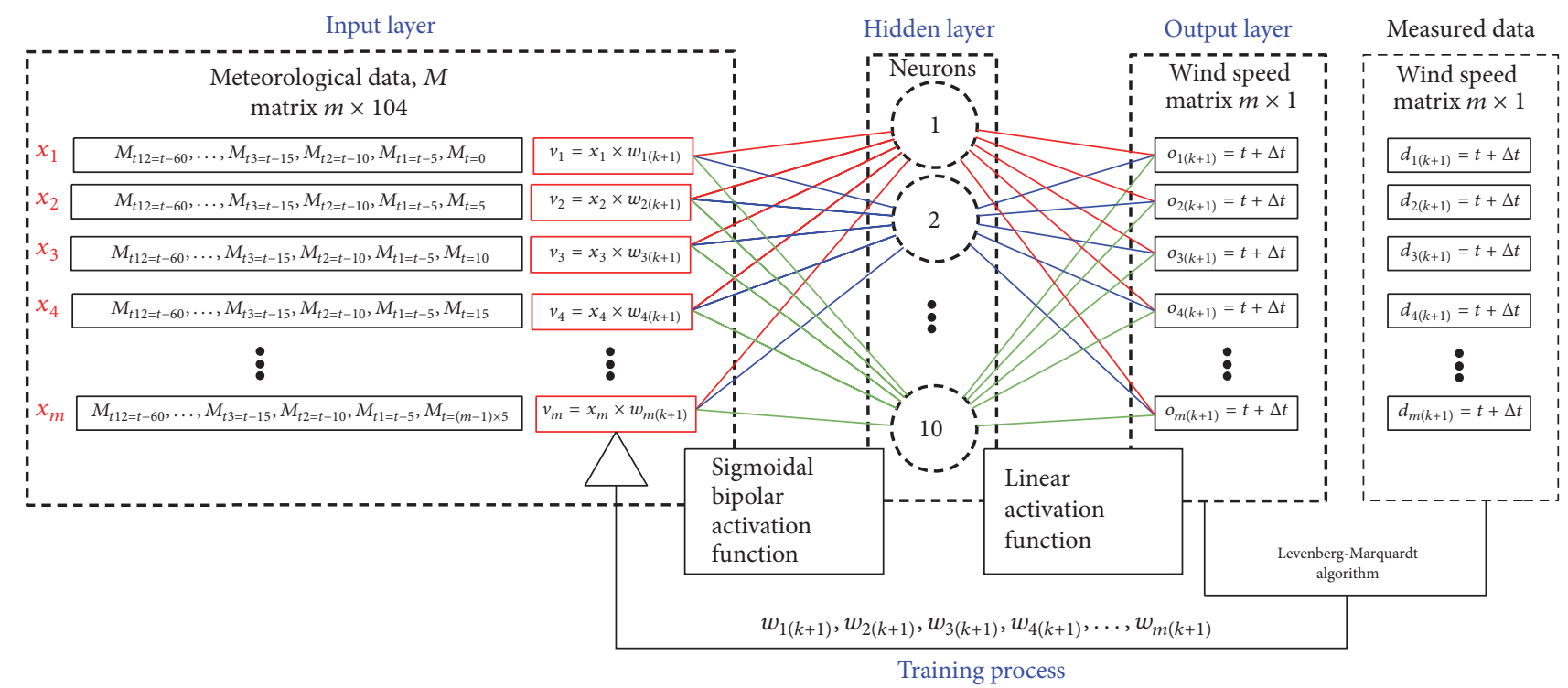

FIGURE 2: Schematic presentation of the artificial neural network prediction model $\left(x_{1,2,3, \ldots, m}\right.$ : input matrix data; $M_{t=(m-1) \times 5}$ : input data set of meteorological data (wind speed, wind direction, wind run, high wind speed, high wind direction, air temperature, air humidity, and air pressure), $w_{1,2,3, \ldots, m}$ : weight coefficient; $v_{k}$ : sum of input matrix and weight coefficient products in $k$ th iteration of the training process; $o_{k}$ : neuron response for $t=\Delta t$ in $k$ th iteration of the training process; $d_{k}$ : measured data).

training process through the iterations of the calculation should be conducted.

2.1.3. Validation. The third group of the model development process refers to the model validation process. This is defined as the model's quality response as the training process is completed. The model should be validated with an earlier prepared set of the input and output data for that purpose (15\% of data) in order to compare the model response with the measured data $[29,30]$. The model response based on the validation data set has to be evaluated graphically and by applying numerical quality measures which are going to be appraised according to each used numerical model quality criteria. Therefore, it is advisable to use at least two numerical quality measures: (i) Mean Squared Error (MSE) and (ii) Coefficient of Determination $\left(r^{2}\right)$.

2.1.4. Evaluation. The last group of the methodology steps refers to the model evaluation process, which is defined as the model's response quality on the data set that is not used in the training or validation process. The model should be evaluated with an earlier prepared set of the input and output data for that purpose ( $15 \%$ of data) in order to compare the model response with the measured data $[29,30]$. The process of the model evaluation is similar to the process of the validation; the only difference is the number of numerical quality measures that are used in that process. In general, it is recommended [31] to use the following measures: (i) Mean Squared Error (MSE), (ii) Root Mean Squared Error (RMSE), (iii) Mean Absolute Error (MAE), (iv) Mean Squared Relative Error (MSRE), (v) Coefficient of Determination $\left(r^{2}\right)$, (vi) Index of Agreement (d), (vii) Percentage to BIAS (PBIAS), and (viii) Root Mean Squared Error to Standard Deviation (RSR).

\section{Results and Discussion}

3.1. Location of the Research Area. The University of Rijeka campus area (hereinafter "Campus") is located in the eastern part of the city of Rijeka, Primorje-Gorski Kotar County, Republic of Croatia, and has an overall area of approximately 28 ha. At the location of the Campus permanently or occasionally stays around five thousand people (students and University employees) on a daily basis [33]. According to the specific geographical location, the Campus is known as a micro location affected by strong wind widely known by name of the Bura. It blows from the land toward the sea (Adriatic coastal area), mainly from the northeast, and by its nature is a strong wind (blowing in gusts). It usually blows for several days, and it is caused by the spilling of cold air from the Pannonian area across the Dinarid mountains toward coastline.

Since 2014, the Campus area has been affected by the wind Bura several times, causing damage to the Campus property and environment as is shown in Figure 3.

Because of flying objects that can cause damage to the property and the environment and hurt people and the powerful gusts of the wind Bura making it impossible for people to move outdoors, the "procedure plan in a case of the emergency caused by stormy wind or hurricane, snow and occurrence of the ice on the University of Rijeka campus" (hereinafter "procedure plan") was adopted in 2015.

3.2. Present State. This procedure plan was enacted according

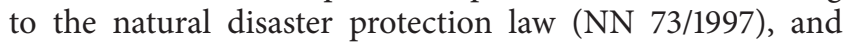




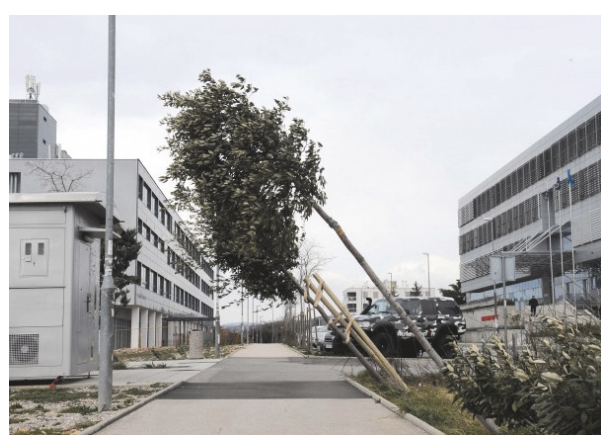

(a)

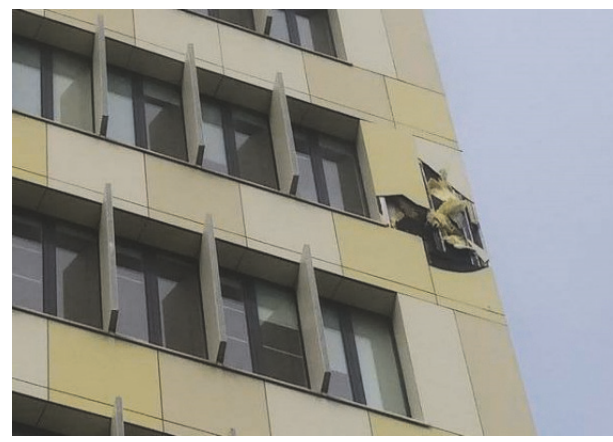

(c)

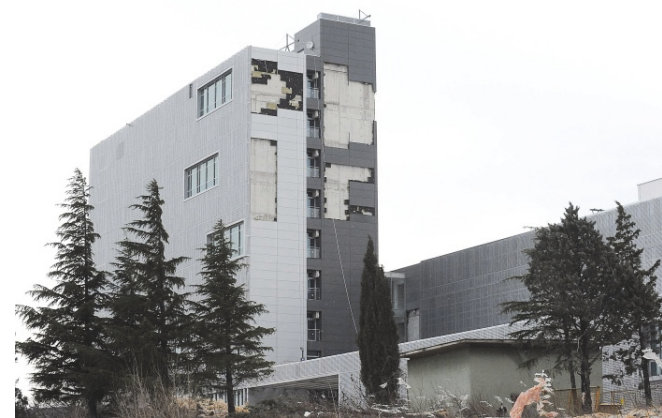

(b)

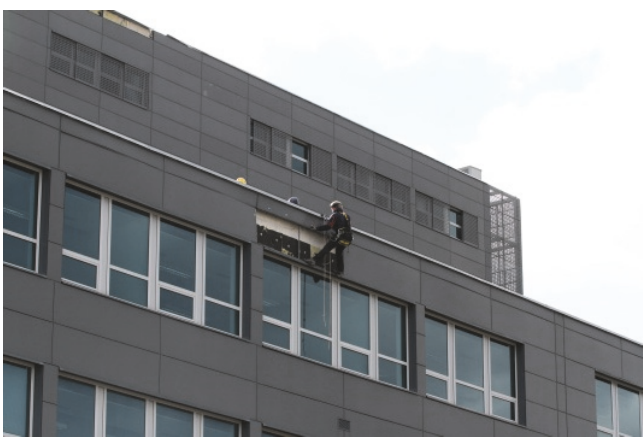

(d)

FIGURE 3: Damage on the Campus property and environment caused by the wind Bura: (a) and (b) damage in March 2015; (c) and (d) damage in January 2017.

the Campus Technical Services (CTS) is in charge of the procedure conduction. CTS has an obligation to monitor (i) wind speed and wind direction on the Campus area (installed measuring equipment) and (ii) the prediction of the Croatian official alerting system through the METEOALARM (Alerting Europe for extreme weather) obtained by the Network of European Meteorological Services (EUMETNET). According to the prediction alerting system and monitoring, CTS declares two levels of alert (Yellow and Red).

In the case of the stormy wind that is classified as wind with ten minutes' mean speed above 8 on a Beaufort scale $(v>18,9 \mathrm{~m} / \mathrm{s})$, the CTS will pronounce the first level of alert as "Yellow alert, stage of preparation for the emergency." The CTS will pronounce the second level of alert defined as "Red alert, extreme danger state of the natural disaster" in the case of a hurricane wind when the ten minutes' mean wind speed reaches 10 on a Beaufort scale $(v>25 \mathrm{~m} / \mathrm{s})$.

In the case of a Yellow alert, it is recommended to close the windows on the buildings and not be in the vicinity of possible flying objects and open windows. In the case of a Red alert, the area of the Campus is closed (postponing teaching and research activities) and people are not allowed to move outside of the buildings. The announcements are disseminated by e-mail to all University employees, through the local radio stations and on the official Internet web pages of every University constituent. The existing system alert is shown in Figure 4.

The implemented procedure plan is very simple and it has several deficiencies. As the procedure is not automated,

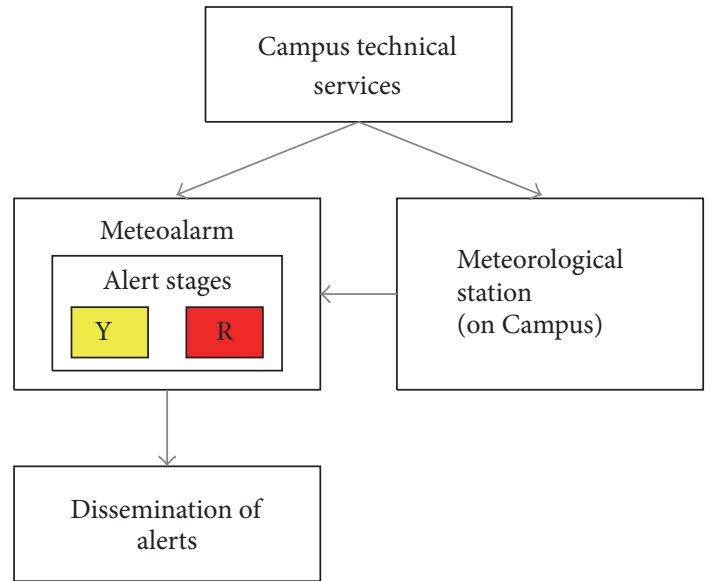

FIGURE 4: Scheme of the "procedure plan in a case of the emergency caused by stormy wind or hurricane, snow and occurrence of the ice on the University of Rijeka campus."

the dissemination of alerts is based on METEOALARM and the alertness of CTS employees to disseminate information. Bigger problems occur in METEOALARM's macro level of prediction as the possible occurrence of strong wind is not sufficiently accurate on the micro level due to the small number of meteorological stations in the region and versatile relief. The University of Rijeka campus area is placed on the specific micro location on which the speed of the wind gusts 


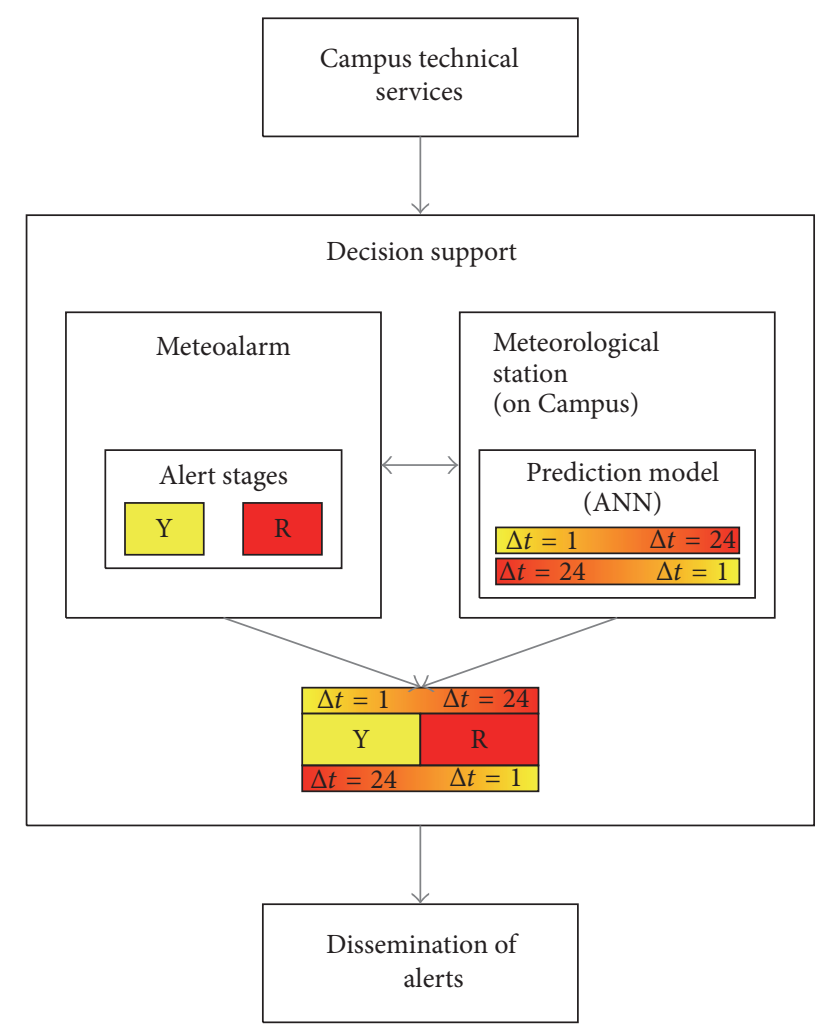

FIGURE 5: Scheme of the proposed EWS.

is usually greater than that in the rest of the wider Rijeka city area. The continuous monitoring and collection of the wind speed and direction data are implemented on the Campus area, but with those measurements it is only possible to see past and real-time meteorological variables such as wind speed and wind direction data. In this case, the real-time measurements are useless to the CTS in order to announce alerts on time, and they can serve only to observe the current state. The aforementioned location weather conditions imply that it is possible to have a stronger wind on Campus than that predicted by METEOALARM, which can potentially have a hazardous impact on both property and people. The dissemination of the announcements is also a weak part of the existing system because of the large number of the students that are not directly alerted.

Therefore, it is necessary to improve the existing alerting system by the implementation of the EWS that is going to be based on both the METEOALARM and the wind speed prediction model and also to improve the procedure plan by the development of the dissemination procedures to obtain better response capability. As the aim and objective is to design and develop an ANN model in order to achieve a successful prediction of wind speed on micro location, the focus of the proposed EWS (Figure 5) is on overlapping micro level prediction with macro level forecast.

As stated, a proposed procedure plan is based on METEOALARM's alert stages and real-time processed data from on-Campus meteorological station. Collected data from the meteorological station serve as input for ANN model, which gives results in the form of predicted wind speed in several time prediction steps. This provides an opportunity to the decision-maker to overlap predictions of ANN model of micro level with macro levels stages of alert in order to disseminate alerts toward stakeholders for specific locations. Therefore, micro level models can give an in-depth prediction on location. This is of great importance when there is a Yellow alert (on the macro level) and the ANN model predicts that conditions on the micro level are Red.

3.3. Data Collection. As mentioned before in the methodology for the development of the model, the first group of steps refers to the establishment of the monitoring. Therefore, continuous data monitoring of the meteorological variables has been established since the beginning of 2015. Data used for modeling purposes dated from January 1, 2015, to June 1, 2017. Meteorological variables used for prediction are (i) wind speed, (ii) wind direction, (iii) wind run, (iv) high wind speed, (v) high wind direction, (vi) air temperature, (vii) air humidity, and (viii) air pressure. They were collected by Vantage Pro 2 meteorological station (manufactured by Davis Instruments Corporation) that is installed on the roof of the Faculty of Civil Engineering. The measurement equipment is obtained by the RISK project (Research Infrastructure for Campus-Based Laboratories at the University of Rijeka; RC.2.2.06-0001). The frequency of data measurement interval is five minutes.

3.4. Development of ANN Wind Prediction Model. The aforementioned collected data is used for the development of the wind speed prediction model for the University of Rijeka campus area. Input (8 variables) and output (1 variable) of the model are selected and then preprocessed. Data is then divided into the sets for the training $(70 \%$ of total data), validation ( $15 \%$ of total data), and evaluation ( $15 \%$ of total data) of the model. Statistics of data used for training, validation, and evaluation processes are shown in Table 1.

After data is prepared, implementation of the ANN model is conducted by MATLAB software (MathWorks, Natick, Massachusetts, USA), and the schematic representation of the model is shown in Figure 6.

Model training is conducted for the time prediction steps: (i) $\Delta t=1 \mathrm{~h}$, (ii) $\Delta t=3 \mathrm{~h}$, (iii) $\Delta t=8 \mathrm{~h}$, (iv) $\Delta t=12 \mathrm{~h}$, and (v) $\Delta t=24 \mathrm{~h}$. After it is trained, the model is visually and numerically validated and evaluated. A comparison of the measured and predicted wind speed in the process of evaluation, according to time prediction step, is presented in Figure 7. On the basis of the visual analysis, it can be observed that the accuracy of the model decreases according to the extension of the prediction time step as expected.

Numerical validation and evaluation of the model are conducted according to the proposed aforementioned methodology. Results of the validation and evaluation processes and assessment of the model quality are shown in Table 2. Since some of the numerical model quality measures criteria are not precisely determined (measures: MSE, RMSE, MAE, MSRE, and RSR), it is recommended that the results should be close to zero. For others, used measures criteria are precise and models are assessed according to them. 
TABLE 1: Statistics of data used for training, validation, and evaluation of the ANN wind prediction model.

\begin{tabular}{|c|c|c|c|c|c|c|c|c|c|}
\hline \multirow[b]{2}{*}{ Statistics* } & \multicolumn{8}{|c|}{ Input layer } & \multirow{2}{*}{$\begin{array}{c}\text { Output layer } \\
\text { Wind speed } \\
{[\mathrm{m} / \mathrm{s}]}\end{array}$} \\
\hline & $\begin{array}{l}\text { Wind } \\
\text { speed } \\
{[\mathrm{m} / \mathrm{s}]}\end{array}$ & $\begin{array}{c}\text { Wind } \\
\text { direction } \\
{[]}\end{array}$ & $\begin{array}{c}\text { Wind run } \\
{[\mathrm{km}]} \\
\end{array}$ & $\begin{array}{l}\text { High wind } \\
\text { speed } \\
{[\mathrm{m} / \mathrm{s}]}\end{array}$ & $\begin{array}{c}\text { High wind } \\
\text { direction } \\
{[]}\end{array}$ & $\begin{array}{c}\text { Air } \\
\text { pressure } \\
{[\mathrm{hPa}]}\end{array}$ & $\begin{array}{c}\text { Air } \\
\text { humidity } \\
{[\%]}\end{array}$ & $\begin{array}{c}\text { Air } \\
\text { temperature } \\
{\left[{ }^{\circ} \mathrm{C}\right]} \\
\end{array}$ & \\
\hline \multicolumn{10}{|c|}{ Model training data ( $70 \%$ of data) } \\
\hline$n$ & 156552 & 156552 & 156552 & 156552 & 156552 & 156552 & 156552 & 156552 & 156552 \\
\hline Max. & 25,9 & NNW & 11,27 & 46 & NNE & 1036,9 & 98 & 41,4 & 25,9 \\
\hline Min. & 0 & I & 0 & 0 & I & 972,5 & 11 & -5 & 0 \\
\hline$\mu$ & 2,68 & I & 0,83 & 4,98 & I & 1015,74 & 59,95 & 15,36 & 2,68 \\
\hline$\sigma$ & 2,53 & 1 & 0,82 & 4,42 & 1 & & 21,16 & 8,2 & 2,53 \\
\hline \multicolumn{10}{|c|}{ Model validation data ( $15 \%$ of data) } \\
\hline$n$ & 33547 & 33547 & 33547 & 33547 & 33547 & 33547 & 33547 & 33547 & 33547 \\
\hline Max. & 21,9 & NNE & 6,57 & 38 & NNE & 1039,4 & 98 & 27,1 & 21,9 \\
\hline Min. & 0 & I & 0 & 0 & I & 995,5 & 7 & $-8,1$ & 0 \\
\hline$\mu$ & 2,65 & / & 0,8 & 5,07 & I & 1021,49 & 65,14 & 8,18 & 2,65 \\
\hline$\sigma$ & 2,35 & 1 & 0,7 & 4,5 & 1 & 8,21 & 21,68 & 5,63 & 2,35 \\
\hline \multicolumn{10}{|c|}{ Model evaluation data ( $15 \%$ of data) } \\
\hline$n$ & 33547 & 33547 & 33547 & 33547 & 33547 & 33547 & 33547 & 33547 & 33547 \\
\hline Max. & 16,1 & NNE & 4,83 & 24,6 & $\mathrm{~N}$ & 1034,7 & 97 & 37,1 & 16,1 \\
\hline Min. & 0 & I & 0 & 0 & I & 997,9 & 14 & 0 & 0 \\
\hline$\mu$ & 2,14 & / & 0,65 & 4,17 & l & 1016,7 & 57,86 & 16,02 & 2,14 \\
\hline$\sigma$ & 1,58 & I & 0,47 & 2,96 & I & 6,06 & 20,36 & 7,71 & 1,58 \\
\hline
\end{tabular}

${ }^{*} n$ = number of observations; Max. = maximum; Min. = minimum; $\mu=$ sample mean; $\sigma=$ standard deviation.

TABLE 2: Performance statistics of the ANN model during validation and evaluation processes.

\begin{tabular}{|c|c|c|c|c|c|c|c|c|c|c|}
\hline \multirow[b]{2}{*}{$\begin{array}{l}\Delta t \\
{[\mathrm{~h}]}\end{array}$} & \multicolumn{2}{|c|}{ Validation } & \multicolumn{8}{|c|}{ Evaluation } \\
\hline & $\begin{array}{c}\text { MSE } \\
{\left[(\mathrm{m} / \mathrm{s})^{2}\right]}\end{array}$ & $\begin{array}{l}r^{2} \\
{[-]} \\
\end{array}$ & $\begin{array}{c}\text { MSE } \\
{\left[(\mathrm{m} / \mathrm{s})^{2}\right]}\end{array}$ & $\begin{array}{c}\text { RMSE } \\
{[\mathrm{m} / \mathrm{s}]}\end{array}$ & $\begin{array}{l}\text { MAE } \\
{[\mathrm{m} / \mathrm{s}]}\end{array}$ & $\begin{array}{c}\text { MSRE } \\
{[-]}\end{array}$ & $\begin{array}{l}r^{2} \\
{[-]}\end{array}$ & $\begin{array}{c}d \\
{[-]}\end{array}$ & $\begin{array}{c}\text { PBIAS } \\
{[\%]}\end{array}$ & $\begin{array}{c}\text { RSR } \\
{[-]}\end{array}$ \\
\hline 1 & 0,075 & 0,993 & 0,058 & 0,158 & 0,113 & 23,34 & 0,987 & 0,998 & 0,503 & 0,105 \\
\hline 3 & 2,033 & 0,951 & 1,505 & 0,736 & 0,581 & 1248,98 & 0,894 & 0,963 & 6,817 & 0,481 \\
\hline 8 & 2,999 & 0,868 & 1,970 & 1,094 & 0,897 & 4365,318 & 0,727 & 0,85 & 14,969 & 0,729 \\
\hline 12 & 3,872 & 0,833 & 2,306 & 1,216 & 1,026 & 3169,53 & 0,669 & 0,727 & 17,302 & 0,794 \\
\hline 24 & 4,985 & 0,572 & 2,741 & 1,382 & 1,088 & 11166,16 & 0,467 & 0,353 & 9,539 & 0,923 \\
\hline
\end{tabular}

Quality Criteria. Very good in bold, good in italic, and poor in bold italic. Model quality criteria according to [31, 32].

Numerical validation and evaluation measures have confirmed that the models with time steps $\Delta t=1 \mathrm{~h}, \Delta t=3 \mathrm{~h}$, and $\Delta t=8 \mathrm{~h}$ have noticeably better prediction possibilities since they are assessed as "very good" and "good" than models with time steps $\Delta t=12 \mathrm{~h}$ and $\Delta t=24 \mathrm{~h}$. Additionally, other measures are very small, near zero, while for the time steps $\Delta t=12 \mathrm{~h}$ and $\Delta t=24 \mathrm{~h}$ they are significantly bigger. Although models with time steps $\Delta t=12 \mathrm{~h}$ and $\Delta t=24 \mathrm{~h}$ show poor quality results, according to visual analysis, they are still showing some prediction indication of an increase or decrease of wind speed, and therefore these predictions can be used, but carefully.
According to the results of performance statistics of the developed ANN model, the decision-maker on micro level can make decisions on time with up to prediction step of $\Delta t=$ $8 \mathrm{~h}$. By overlapping the macro level forecast with this micro level prediction, they can control the accurate dissemination of alerts in a specific area.

\section{Conclusions}

This paper presents an application of artificial neural networks in the predicting process of wind speed and its implementation in early warning system as a decision support 


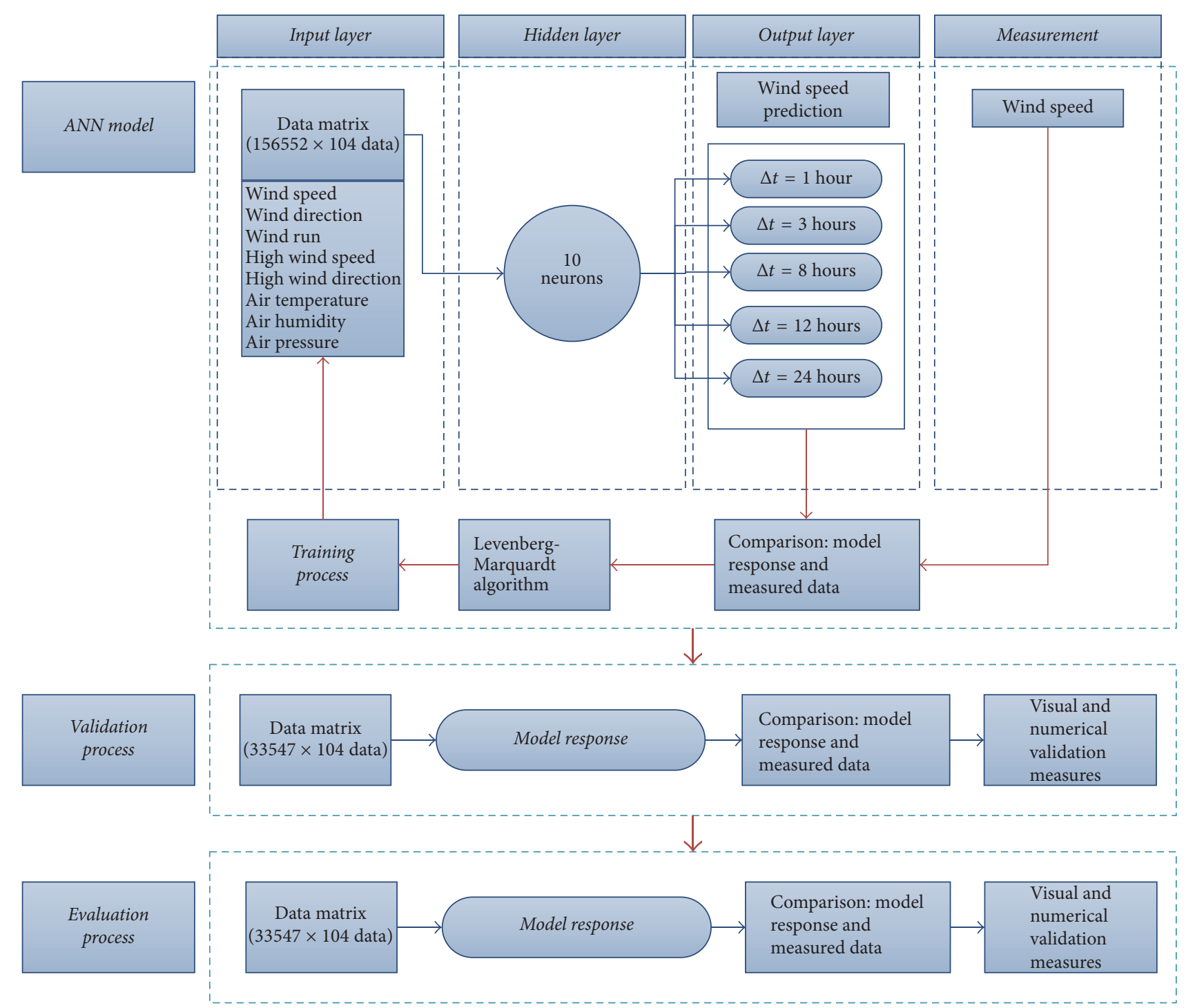

FigurE 6: Schematic representation of the ANN wind speed prediction model based on $[14,15]$.

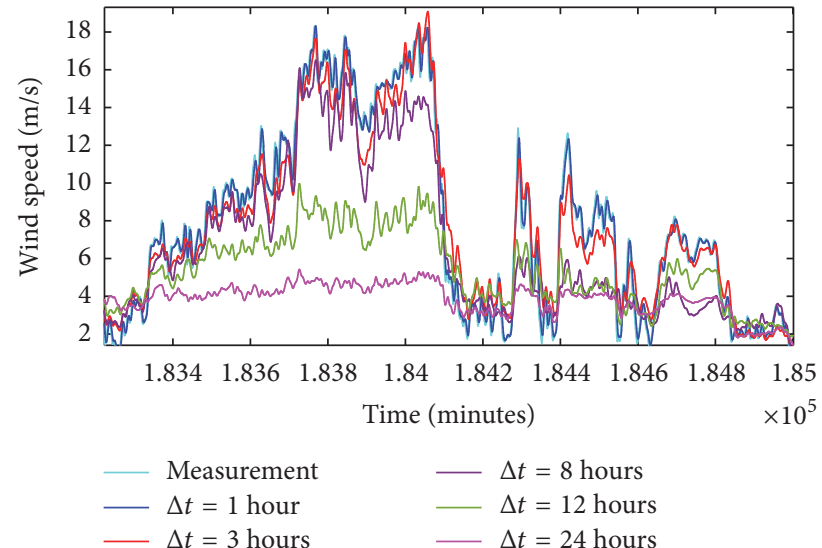

Figure 7: Comparison of the measured wind speed and model response (five minutes' time step) in process of the model evaluation according to time prediction steps $(\Delta t=1 \mathrm{~h}, \Delta t=3 \mathrm{~h}, \Delta t=8 \mathrm{~h}$, $\Delta t=12 \mathrm{~h}$, and $\Delta t=24 \mathrm{~h}$ ). tool. The main objectives of this research were to develop the model to achieve a successful prediction of wind speed on micro location based on data from meteorological station and to implement it in model base to serve as decision support tool in the proposed early warning system.

Data gathered by a local meteorological station during a 30 -month period ( 8 variables) was used in the prediction process of wind speed. The model is developed for 5-time prediction steps: (i) $\Delta t=1 \mathrm{~h}$, (ii) $\Delta t=3 \mathrm{~h}$, (iii) $\Delta t=8 \mathrm{~h}$, (iv) $\Delta t=12 \mathrm{~h}$, and (v) $\Delta t=24 \mathrm{~h}$. The evaluation of the model shows very good prediction possibilities for time steps $\Delta t=1 \mathrm{~h}, \Delta t=3 \mathrm{~h}$, and $\Delta t=8 \mathrm{~h}$ and therefore enables the early warning system implementation.

The performed research indicates that it is possible and desirable to apply artificial neural network for the prediction process on the micro locations, because that type of model is valuable and accurate tool to be implemented in model base to support future decisions in early warning systems. 
The complete evaluation and functionality of the proposed early warning system and artificial neural network model can be done, after its implementation on the University of Rijeka campus (Croatia) is conducted.

\section{Conflicts of Interest}

The authors declare that there are no conflicts of interest regarding the publication of this paper.

\section{Acknowledgments}

The research for this paper was conducted within the project "Research Infrastructure for Campus-Based Laboratories at the University of Rijeka," which is cofunded by the European Union under the European Regional Development Fund (RC.2.2.06-0001), as well as a part of the scientific project "Water Resources Hydrology and Floods and Mud Flow Risks Identification in the Karstic Area" financed by the University of Rijeka (13.05.1.1.03).

\section{References}

[1] A. De Bono, B. Chatenoux, C. Herold, and P. Peduzzi, Global Assessment Report on Disaster Risk Reduction 2013: From Shared Risk to Shared Decision Support for Risk Management: Design of EWS 13 Value-The Business Case for Disaster Risk Reduction, UNISDR, Geneva, Switzerland, 2013.

[2] Harvard Humanitarian Initiative et al. Disaster Relief 2.0, "The future of information sharing in humanitarian emergencies," HHI; United Nations Foundation; OCHA; The Vodafone Foundation, Washington DC, USA, 2010.

[3] J. C. Gaillard and J. Mercer, "From knowledge to action: Bridging gaps in disaster risk reduction," Progress in Human Geography, vol. 37, no. 1, pp. 93-114, 2013.

[4] J. Weichselgartner and R. Kasperson, "Barriers in the sciencepolicy-practice interface: Toward a knowledge-action-system in global environmental change research," Global Environmental Change, vol. 20, no. 2, pp. 266-277, 2010.

[5] E. L. Quarantelli, "Disaster crisis management: a summary of research findings," Journal of Management Studies, vol. 25, no. 4, pp. 373-385, 1988.

[6] UN/ISDR platform for the promotion of early warning (PPEW) and un Secretairat of the International strategy for disaster reduction (UN/ISDR), "Developing early warning system: A checklist," in Proceedings of the EWC III Third International Conference on Early Warning: From Concept to Action, Bonn, Germany, March, 2006.

[7] L. Lin, J. T. Eriksson, H. Vihriala, and L. Soderlund, "Predicting wind behavior with neural networks," in Proceedings of the 1996 European Wind Energy Conference, pp. 655-658, Goteborg, Sweden, May 1996.

[8] M. A. Mohandes, S. Rehman, and T. O. Halawani, "A neural networks approach for wind speed prediction," Journal of Renewable Energy, vol. 13, no. 3, pp. 345-354, 1998.

[9] M. C. Alexiadis, P. S. Dokopoulos, H. S. Sahsamanoglou, and I. M. Manousaridis, "Short-term forecasting of wind speed and related electrical power," Solar Energy, vol. 63, no. 1, pp. 61-68, 1998.

[10] P. M. Fonte, G. X. Silva, and J. C. Quadrado, "Wind speed prediction using artificial neural networks," WSEAS Transactions on Systems, vol. 4, no. 4, pp. 379-383, 2005.
[11] M. Monfared, H. Rastegar, and H. M. Kojabadi, "A new strategy for wind speed forecasting using artificial intelligent methods," Journal of Renewable Energy, vol. 34, no. 3, pp. 845-848, 2009.

[12] S. A. Pourmousavi Kani and M. M. Ardehali, "Very short-term wind speed prediction: a new artificial neural network-Markov chain model," Energy Conversion and Management, vol. 52, no. 1, pp. 738-745, 2011.

[13] Q. Zhou, T. Xiong, M. Wang, C. Xiang, and Q. Xu, "Diagnosis and early warning of wind turbine faults based on cluster analysis theory and modified ANFIS," Energies, vol. 10, no. 7, article 898, 2017.

[14] I. Sušanj, N. Ožanić, and I. Marović, "Methodology for developing hydrological models based on an artificial neural network to establish an early warning system in small catchments," Advances in Meteorology, vol. 2016, Article ID 9125219, 14 pages, 2016.

[15] I. Sušanj, Development of the hydrological rainfall-runoff model based on artificial neural network in small catchments [Ph.D. thesis], University of Rijeka, Faculty of Civil Engineering, Rijeka, Croatia, 2017.

[16] A. Asemi, A. Safari, and A. Asemi Zavareh, “The role of management information system (MIS) and decision support system (DSS) for manager's decision making process," International Journal of Business and Management, vol. 6, no. 7, pp. 164-173, 2011.

[17] I. Marovic, Decision support system in real estate value management [Ph.D. thesis], University of Zagreb, Faculty of Civil Engineering, Zagreb, Croatia, 2013.

[18] N. Jajac, Design of decision support systems in the management of infrastructure systems of the urban environment, [M.S. thesis], University of Split, Faculty of Economics, Split, Croatia, 2007.

[19] N. Jajac, S. Knezic, I. Marovic, S. Knezić, and I. Marović, "Decision support system to urban infrastructure maintenance management," Organization, Technology \& Managament in Construction, vol. 1, no. 2, pp. 72-79, 2009.

[20] E. Turban, Decision Support and Expert Systems: Management Support Systems, Macmillan Publishing Company, New York, NY, USA, 1993.

[21] M. H. Glantz, Usable Science 8: Early Warning Systems: Do's and Don'ts, Report of Workshop, Shanghai, China, October 2003.

[22] Millennium Ecosystem Assessment, Ecosystems and Human Well-Being: A Framework for Assessment, Island Press, Washington, DC, USA, 2003.

[23] P. A. Schrodt and D. J. Gerner, "The impact of early warning on institutional responses to complex humanitarian crises," in Proceedings of the Third Pan-European International Relations Conference and Joint Meeting with the International Studies Association, Vienna, Austria, September 1998.

[24] P. Hall, "Early warning systems: Reframing the discussion," Australian Journal of Emergency Management, vol. 22, no. 2, 2007.

[25] UN/ISDR International Strategy for Disaster Reduction, "Hyogo framework for action 2005-2015: building the resilience of nations and communities to disasters," in Proceedings of the World Conference on Disaster Reduction, Hyogo, Japan, January, 2005.

[26] T. Comes, B. Mayag, and E. Negre, "Decision support for disaster risk management: integrating vulnerabilities into earlywarning systems," in Proceedings of the International Conference on Information Systems for Crisis Response and Management in Mediterranean Countries, pp. 178-191, Springer International Publishing, Cham, Germany, October 2014. 
[27] V. V. Krzhizhanovskaya, G. S. Shirshov, and N. B. Melnikova, "Flood early warning system: design, implementation and computational modules," Procedia Computer Science, vol. 4, pp. 106-115, 2011.

[28] H. R. Maier, A. Jain, G. C. Dandy, and K. P. Sudheer, "Methods used for the development of neural networks for the prediction of water resource variables in river systems: current status and future directions," Environmental Modeling and Software, vol. 25, no. 8, pp. 891-909, 2010.

[29] H. B. Demuth and M. H. Beale, Neural Network ToolboxTM User's Guide, The MathWorks, INC., 2004.

[30] M. T. Hagan, H. B. Demuth, M. H. Beale, O. De Jes, and O. De Jesús, Neural Network Design (20), PWS Publishing Company, Boston, Mass, USA, 1996.

[31] R. Abrahart, P. E. Kneale, and L. M. See, Neural Networks for Hydrological Modelling, Taylor \& Francis Group, London, UK, 2004.

[32] P. Matić, Short-term forecasting of hydrological inflow by use of the artificial neural networks [Ph.D. thesis], University of Split, Faculty of Electrical Engineering, Mechanical Engineering And Naval Architecture, Split, Croatia, 2014.

[33] S. Grbac, L. Malnar, A. Vorkapić, D. Car-Pušić, and I. Marović, "'Preliminary analysis of the spatial attributes affecting students' quality of life at the University of Rijeka," in Proceedings of the People, Buildings and Environment 2016, an International Scientific Conference, vol. 4, pp. 109-117, Luhačovice, Czech Republic, 2016. 


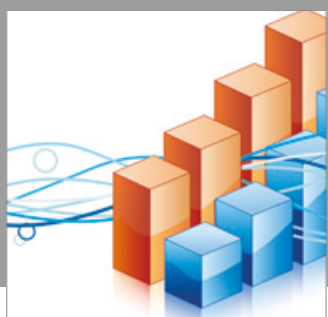

Advances in

Operations Research

vatersals

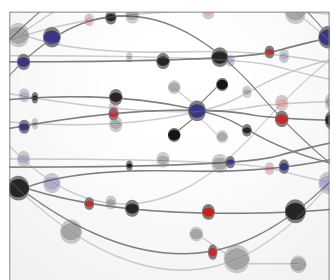

\section{The Scientific} World Journal
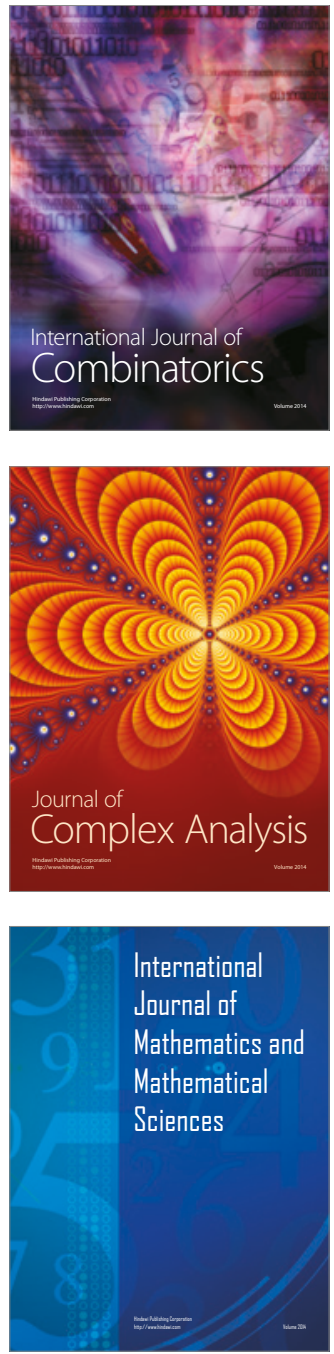
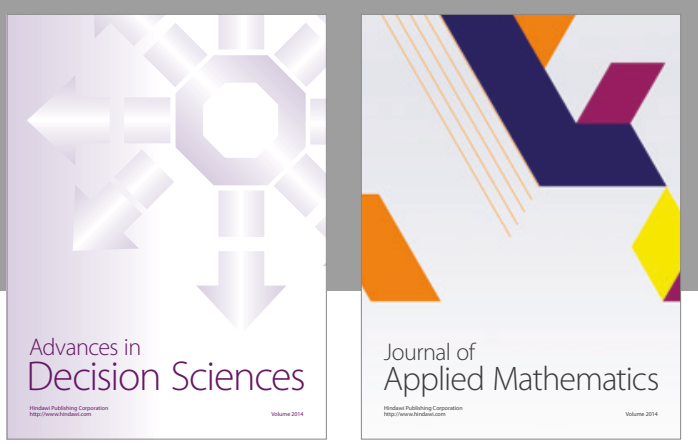

Algebra

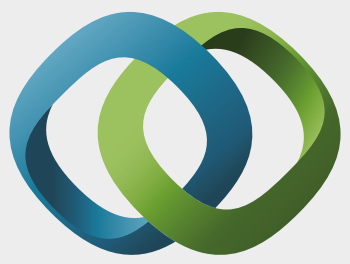

\section{Hindawi}

Submit your manuscripts at

https://www.hindawi.com
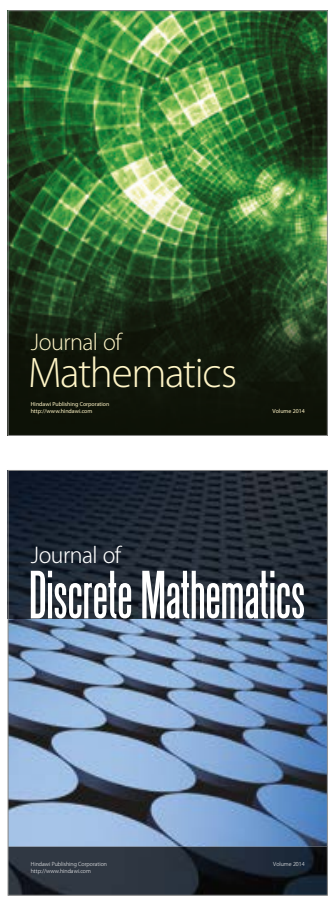

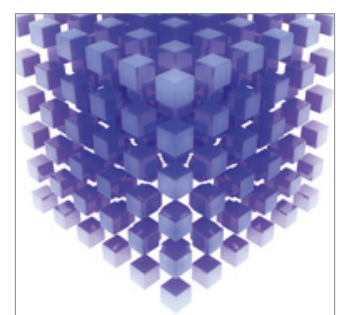

Mathematical Problems in Engineering
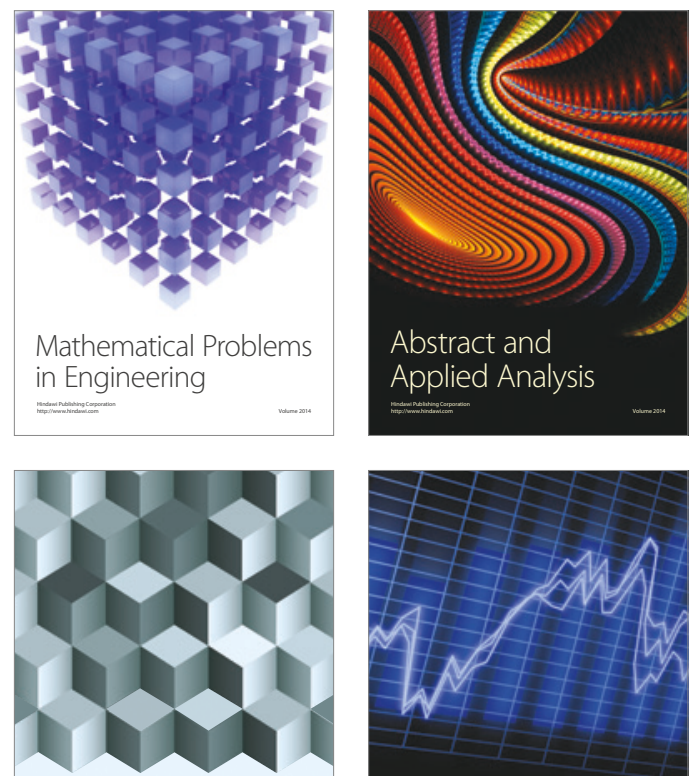

Journal of

Function Spaces

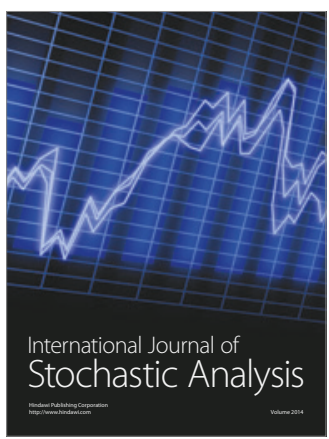

Probability and Statistics
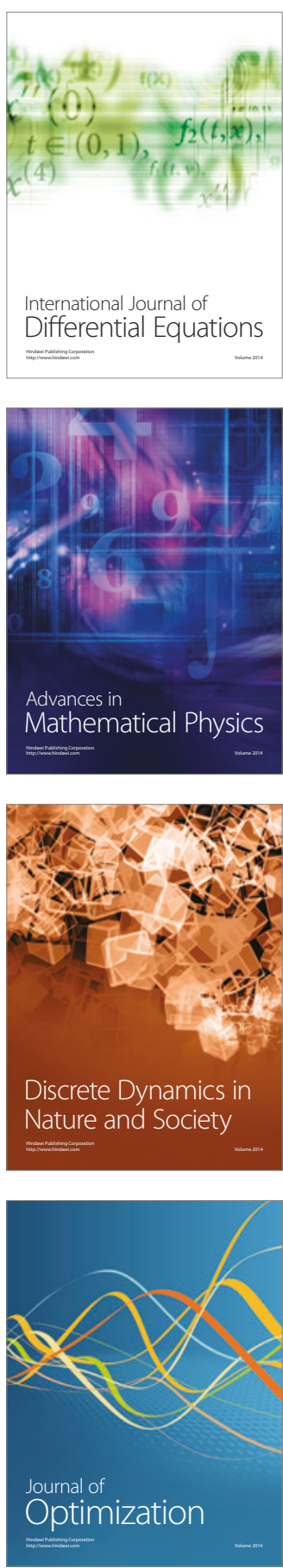